Fakultas Pertanian UNIVERSITAS TRIDINANTI

PALEMBANG

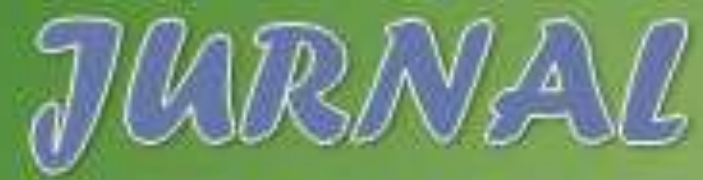

슬

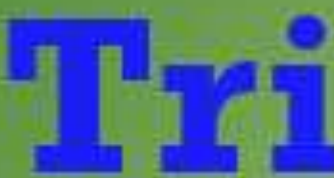


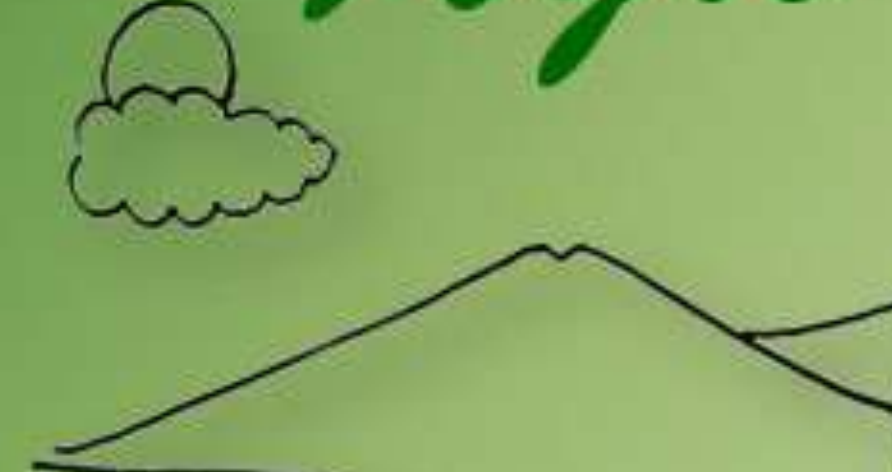


\section{Jurnal TRIAGRO}

FaKULTAS PERTAMLAO UNVERSITAS TRIDINARTI PAIEMRARG

\section{Dewan Redaksi}

Pelindung

Pembina

Pimpinan Umum

Ketua Penyunting

Penyunting Pelaksana

Penyunting Ahli

Dewan Redaksi

Distribusi \& Website
: Dr. Ir. Hj. Manisah MP (Rektor)

: Dr. Nasir Sp. M.Si

: Miranty Trinawaty SP. M.Si

: Dr.Ir.Nur Ahmadi

- Prof. Dr. Edizal M.S

- Dr. Ir. Nur Ahmadi

- Dr.Ir Faridatul Mukminah M.Sc

- Dr. Ir Ruarita RK. MP

: 1. Dr. Ir. Nurmayulis , MP (Universitas Sultan Ageng Tirtayasa)

2. Dr. Munajat, SP. M.Si (Universitas Baturaja)

:

- Ir. Setiawaty MP

- $\quad$ Ir. Meryanto, M.Si

- Ir. Rostian Nafery, M.Si

- Ir. Ursula Damayanti, MP

- Ir. Ekanovi Aktiva, MM

- Ir. Hj. Yuliantina Azka, MP

: Nova Tri Buyana, Sp 


\section{DAFTAR ISI}

1 PENGARUH PERBEDAAN JENIS MATA ENTRES DAN KLON TERHADAP PERTUMBUHAN BIBIT KARET (Hevea brasiliensis Muell Arg.)DI POLYBAG

Meriyanto, Bastani S., and Indah L

2 RESPON BEBERAPA VARIETAS PADI (Oriza Sativa L)TERHADAP PEMBERIAN BEBERAPA JENIS PUPUK DI TANAH PASANG SURUT

\section{8} Ida Aryani

PENGARUH PERLAKUAN BENIH DAN MEDIA TANAM TERHADAP

3 PERKECAMBAHAN DAN PERTUMBUHAN BENIH SALAK (Salacca edulis Reinw) DI POLIBEG

Zulkarnain Husny, Ridwan Hanan, Hendri

4 ANALISIS PEMASARAN BAHAN OLAH KARET (BOKAR) DAN PENDAPATAN PETANI KARET (Studi Kasus di Desa Surya Adi Kecamatan Mesuji Kabupaten Ogan Komering Ilir)

Nur Ahmadi, Gusti Fitriyana, Tri Sudoni.

5 KONTRIBUSI PENDAPATAN USAHATANI PADI LEBAK TERHADAP TOTAL PENDAPATAN KELUARGA (Kasus di Desa Arisan Musi Timur 33 Kecamatan Muara Belida Kabupaten Muara Enim)

Setiawati, Denny Herdian, Melda Santi

6 NALISIS HARGA POKOK DAN KEUNTUNGAN USAHATANI CABAI 46 MERAH BESAR (Capsicum Annuum L) DI DESA TALANG BULUH KECAMATANTALANG KELAPA KABUPATEN BANYUASIN

Ursula Damayanti, Denni Herdian 


\section{Pedoman Penulisan Artikel Ilmiah Jurnal TRIAgro Fakultas Pertanian Universitas Tridinanti Palembang}

1. Jurnal ini direncanakan terbit tiga kali dalam setahun, terbuka untuk umum yang ingin mempublikasikan hasil karyanya. Artikel yang ditulis meliputi hasil penelitian di bidang sains.

2. Semua naskah makalah disertai pernyataan bahwa naskah tersebut belum pernah diterbitkan sebelumnya oleh penerbit lain.

3. Setiap naskah yang diterima akan ditinjau/ditelaah oleh ahli dibidangnya sebelum diterbitkan.

4. Naskah tidak dapat diterima jika mengandung unsur politik, komersialisme dan subyektifitas yang berlebihan.

5. Simbol dan terminologi yang digunakan adalah simbol dan terminologi yang lazim digunakan di bidang keahlian masin-masing.

6. Penulis menyetujui untuk mengalihkan hak ciptanya ke redaksi, jika naskahnya diterima untuk diterbitkan.

7. Artikel ditulis dalam bahasa Indonesia atau Inggris. Minimal 10 halaman dan maksimal 15 halaman, termasuk daftar pustaka dan lampiran : ukuran kertas A4, spasi 1,5, margin kiri $4 \mathrm{~cm}$, margin kanan, atas dan bawah masing-masing $3 \mathrm{~cm}$, menggunakan Times New Roman Font 11.

8. Artikel diketik dengan program MS Word, penulis dimohon mengirimkan satu print out dan satu CD yang berisi artikel, cantumkan alamat email dan no telepon/hp penulis untuk keperluan konfirmasi tentang tulisan yang dikirimkan ke redaksi.

9. Artikel dilengkapi :

Abstrak tidak lebih dari 200 kata dengan kata-kata kunci, biodata singkat penulis dan identitas penelitian dicantumkan sebagai cat kaki pada halaman pertma artikel.

10. Penulisan daftar pustaka mengikuti penulisan yang baik dan benar 


\section{KATA PENGANTAR}

Terima kasih atas berkah Tuhan Yang Maha Kuasa dan Rahmat-Nya, maka Jurnal TriAgro Fakultas Pertanian Universitas Tridinanti Palembang ini dapat diterbitkan. Jurnal ini diharapkan dapat menampung informasi dunia pertanian modern dan menyebarkan informasi di lingkup pertanian baik secara umum maupun khusus, penerbitan jurnal ini diharapkan dapat menjadi sarana untuk menampung tulisan-tulisan ilmiah pertanian.

Dewan redaksi mengucapkan terima kasih kepada semua pihak yang telah memerikan bantuan teknis maupun non teknis untuk terbitnya jurnal TriAgro ini. Dewan redaksi sangat mengharapkan partisipasi peneliti untuk menyumbangkan tulisannya ke jurnal TriArgro ini guna menjaga kelancaran penerbitan, yaitu dua kali setahun.

Dewan redaksi mengucapkan terima kasih kepada Bapak/Ibu/Saudara yang telah berpartisipasi pada jurnal edisi ini. Semoga Jurnal ini dapat memberikan manfaat kepada Bapak/Ibu/Saudara semuanya. 


\title{
ANALISIS PEMASARAN BAHAN OLAH KARET (BOKAR) DAN PENDAPATAN PETANI KARET \\ (Studi Kasus di Desa Surya Adi Kecamatan Mesuji Kabupaten Ogan Komering Ilir)
}

\author{
MARKETING ANALYSIS OF RUBBER MATERIAL ( BOKAR ) INCOME AND \\ RUBBER FARMERS \\ (Case Study in the village of Surya Adi Mesuji Subdistrict Ogan Komering Ilir )
}

\author{
NUR AHMADI ${ }^{1 *}$ GUSTI FITRIYANA $^{1)}$ TRI SUDONI ${ }^{2)}$ \\ ${ }^{1)}$ Dosen Program Studi Agrobisnis Fakultas Pertanian Universitas Tridinanti \\ Palembang
}

\begin{abstract}
This study aims to assess treatment systems, marketing systems Sports Rubber Materials (Bokar) and counting and analyzing the rubber farmers' income at farm level by the farmers in the village of Adi Surya Mesuji Subdistrict Ogan Ogan Ilir. The results of this study are also expected to be useful for parties involved, especially for farmers as a material consideration and enter in pursuit of rubber farming, in order to know and Marketing Materials Processing System Sport Rubber (Bokar) and can increase the income of rubber farmers. The method used in this study is a survey, data collection is done by taking a sample portion of the population is large enough and done interviews as well as data processing. The results of the survey and field observation known to the processing performed rubber farmers in the village of Surya Adi District of Mesuji Ogan Komering Ilir do with vinegar severe, fertilizer SP 36 and alum as a coagulant latex, marketing bokar not well organized it is caused by the marketing chain bokar long and low quality.
\end{abstract}

Keys word : Rubber, BOKAR, Processing and Marketing

\section{RINGKASAN}

Penelitian ini bertujuan untuk mengkaji sistem pengolahan, sistem pemasaran Bahan Olah Karet (Bokar) dan menghitung serta menganalisis pendapatan petani karet di tingkat petani yang dilakukan petani di Desa Surya Adi Kecamatan Mesuji Kabupaten Ogan Komering Ilir. Hasil penelitian ini juga diharapkan dapat berguna bagi pihak terkait terutama bagi petani sebagai bahan pertimbangan dan masukkan dalam mengusahakan usaha tani karet, agar mengetahui Sistem Pengolahan dan Pemasaran Bahan Olah Karet (Bokar) serta dapat meningkatkan pendapatan petani karet. Metode yang digunakan dalam penelitian ini adalah survey, pengumpulan data yaitu dilakukan dengan mengambil sebagian sampel dari populasi yang cukup besar dan dilakukan wawancara serta pengolahan data. Hasil penelitian dari survei dan pengamatan di lapangan diketahui pengolahan yang dilakukan petani karet di Desa Surya Adi Kecamatan Mesuji Kabupaten Ogan Komering Ilir dilakukan dengan cuka parah, pupuk SP 36 dan tawas sebagai pembeku lateks, pemasaran bokar belum terorganisir dengan baik hal ini sebabkan oleh rantai pemasaran yang panjang dan mutu bokar yang rendah.

Kata Kunci : Karet, BOKAR, Pengolahan dan Pemasaran 


\section{PENDAHULUAN}

Karet alam merupakan salah satu komoditas pertanian yang penting untuk Indonesia dan lingkup Internasional. Di Indonesia, karet merupakan salah satu hasil pertanian yang banyak menunjang perekonomian Negara. Hasil devisa yang di peroleh dari karet cukup besar. Luas areal kebun karet seluas 3,46 juta ha sedangkan Thailand 3,6 juta ha dan Malaysia 1,07 juta ha. Pada tahun 2012 produksi karet Indonesia sebesar 1,08 ton/ha, Thailand 3,6 juta ton dan Malaysia 0,9 juta ton. Produktivitas karet Indonesia masih rendah yaitu sebesar 1,08 ton/ha dibandingkan India yang mencapai 1,81 ton/ha sedangkan Thailand dan Vietnam mencapai 1,72 ton/ha. Adapun tenaga kerja yang diserap di sektor on farm $\pm 2,1$ juta KK dan di sektor off farm \pm 100 ribu orang. Berbagai produk bernilai tambah tinggi dapat dihasilkan dari karet seperti ban, sarung tangan, komponen otomotif, komponen elektronika dan barang keperluan rumah tangga serta lain-lain (Gapkindo Sumsel, 2014).

Sejumlah lokasi di Indonesia memiliki keadaan lahan yang cocok untuk perkebunan karet, sebagian besar di wilayah Sumatera dan Kalimantan. Sumatera selatan merupakan penghasil karet alam yang cukup penting di Indonesia.Ogan Komering Ilir tergolong daerah dengan aktifitas ekonomi utama pada perdagangan dan jasa yang dapat dilihat dari besarnya aktifitas ekonomi masyarakat yang di dominasi oleh kedua sektor ini. Tetapi bila dilihat dari penggunaan lahannya, maka sebanyak 71,24\% digunakan untuk usaha pertanian yang diperuntukkan untuk tegal/ladang/huma, perkebunan, padi, palawija, buahbuahan, kehutanan dan perikanan (Budiono, 2011).Berdasarkan

beberapa komoditas perkebunan penting di Indonesia, karet alam tumbuh cukup pesat, diikuti oleh komoditi lainnya seperti kelapa sawit dan kakao. Pertumbuhan yang sangat pesat dari ketiga komoditas ini akan mampu mendorong perluasan areal dan sejalan dengan ini pula produksi perkebunan akan semakin meningkat secara konsisten.

Karet merupakan tanaman yang berasal dari Amerika Latin,khususnya Brazil dengan nama ilmiah Havea Brasiliensis. Sebelum di populerkan tanaman budi daya, penduduk asli Amerika Selatan, Afrika dan Asia telah memanfaatkan beberapa jenis tanaman penghasil getah. Getah yang mirip lateks juga dapat di peroleh dari tanamam Castillaelastica Family Moraceae (Setiawan,2005). Dalam Proses pengolahan bokar, lateks tersebut kadang-kadang diperlakukan tidak seharusnya, misalnya dikotori atau dicampur dengan benda-benda lain agar menjadi lebih banyak atau terkesan lebih lama disimpan. Bahan olah karet yang sudah dikotori tersebut kemudian dijual ke pedagang dan seterusnya ke pabrik pengolahan untuk menjadi barangbarang yang kemudian di ekspor ke luar negeri. Di pabrik pengolahan, bahan olah yang kotor tersebut terlebih dahulu dibersihkan, diseragamkan, dikeringkan, diperiksa kualitasnya sampai memenuhi persyaratan kemudian dipak dan selanjutnya diekspor. Benda-benda asing yang dimasukkan tersebut kadang-kadang mencapai jumlah yang sangat banyak dan tidak 
mungkin dibersihkan di pabrik pengolahan karena telah merusak mutu karet asalnya.

Pemasaran karet serta biaya yang akan dikeluarkan petani dalam proses produksi serta membawanya menjadi produk disebut biaya produksi. Termasuk didalamnya barang yang dibeli dan jasa yang di bayar didalam maupun diluar usaha tani (Winardi, 2007). Biaya produksi ditambahkan juga oleh Rosyidi (2001), merupakan nilai semua faktor produksi yang dipergunakan untuk menghasilkan output. Biaya produksi dapat dibedakan menjadi dua macam berdasarkan jangka waktu produksinya.

Indonesia memiliki areal kebun karet seluas 3,46 juta ha sedangkan Thailand 3,6 juta ha dan Malaysia 1,07 juta ha. Pada tahun 2012 produksi karet Indonesia sebesar 1,08 ton/ha, Thailand 3,6 juta ton dan Malaysia 0,9 juta ton. Produktivitas karet Indonesia masih rendah yaitu sebesar 1,08 ton/ha dibandingkan India yang mencapai 1,81 ton/ha sedangkan Thailand dan Vietnam mencapai 1,72 ton/ha. Adapun tenaga kerja yang diserap di sektor on farm $\pm 2,1$ juta KK dan di sektor off farm \pm 100 ribu orang. Berbagai produk bernilai tambah tinggi dapat dihasilkan dari karet seperti ban, sarung tangan, komponen otomotif, komponen elektronika dan barang keperluan rumah tangga serta lain-lain (Gapkindo Sumsel, 2014).

\section{Tujuan}

Penelitian ini bertujuan untuk mengkaji sistem pemasaran Bahan Olah Karet (Bokar) dan menghitung serta menganalisis pendapatan petani karet di tingkat petani yang dilakukan petani di Desa Surya Adi
Kecamatan Mesuji Kabupaten Ogan Komering Ilir.

\section{Hipotesis}

Berdasarkan rumusan permasalahan dan tinjauan teoritis dalam penelitian, maka dapat dirumuskan hipotesisnya adalah diduga Sistem Pemasaran Bahan Olah Karet (Bokar) di tingkat petani di Desa Surya Adi Kecamatan Mesuji Kabupaten Ogan Komering Ilir terorganisir dengan baik.

\section{BAHAN DAN METODE}

Metode yang digunakan dalam penelitian ini adalah survey, yaitu dilakukan dengan mengambil sebagian sampel dari populasi yang cukup besar dan dilakukan wawancara langsung dengan petanipetani karet yang ada di Kelurahan Surya Adi. Penggunaan metode ini dimaksudkan untuk mengadakan pengamatan secara menyeluruh untuk memperoleh fakta-fakta dan gejala-gejala yang ada dan mencari keterangan-keterangan secara faktual dari daerah contoh yang diteliti.

Data yang diperlukan dalam penelitian ini adalah data primer dan data sekunder. Data primer diperoleh dengan observasi dan wawancara langsung di lapangan dengan petani contoh, menggunakan daftar pertanyaan. Data primer yang dikumpulkan meliputi data identitas petani, luas lahan, peralatan produksi yang digunakan, harga faktor produksi dan biaya produksi, jumlah produksi, harga jual dan keterangan lain yang berhubungan dengan penelitian. Data sekunder diperoleh dari instansi-instansi yang terkait seperti Dinas Perkebunan dan literatur yang berhubungan dengan penelitian ini. 
Data yang diperoleh dan lapangan akan diolah ke dalam bentuk tabel setelah itu dilanjutkan dengan analisis deskriptif untuk menjawab tujuan pertama dan kedua dengan memaparkan hasil yang didapat dalam bentuk uraian yang sistematis untuk menjawab menganalisis sistem pengolahan dan pemasaran. Untuk menjawab tujuan ketiga menganalisis pendapatan petani karet dilakukan dengan analisis tabulasi dan matematika sederhana. Adapun rumus yang digunakan adalah :

a. Total Biaya

$\mathrm{TC}=\mathrm{TFC}+\mathrm{TVC}$

Dimana :

TC : Total Biaya/Total Cost (Rp/th)
TF: Total Biaya Tetap(Rp/th)

TVC: Total Biaya Variabel (Rp/thn)

b. Penerimaan

$\mathrm{TR}=\mathrm{P} . \mathrm{Q}$

Dimana :

TR : Total Penerimaan (Rp/kg)

$\mathrm{P}$ : Harga Produk/Price $(\mathrm{Rp} / \mathrm{kg})$

Q : Jumlah produk/Quantity $(\mathrm{kg})$

c. Pendapatan

$\mathrm{PD}=\mathrm{TR}-\mathrm{TC}$

Dimana :

PD : Pendapatan (Rp/th).

TR: Total Penerimaan (Rp/th).

$\mathrm{TC}:$ Total Biaya(Rp/th)

\section{Model Pendekatan}

Model pendekatan yang digunakan dalam penelitian ini adalah model diagramatik yang disajikan pada gambar di bawah ini :

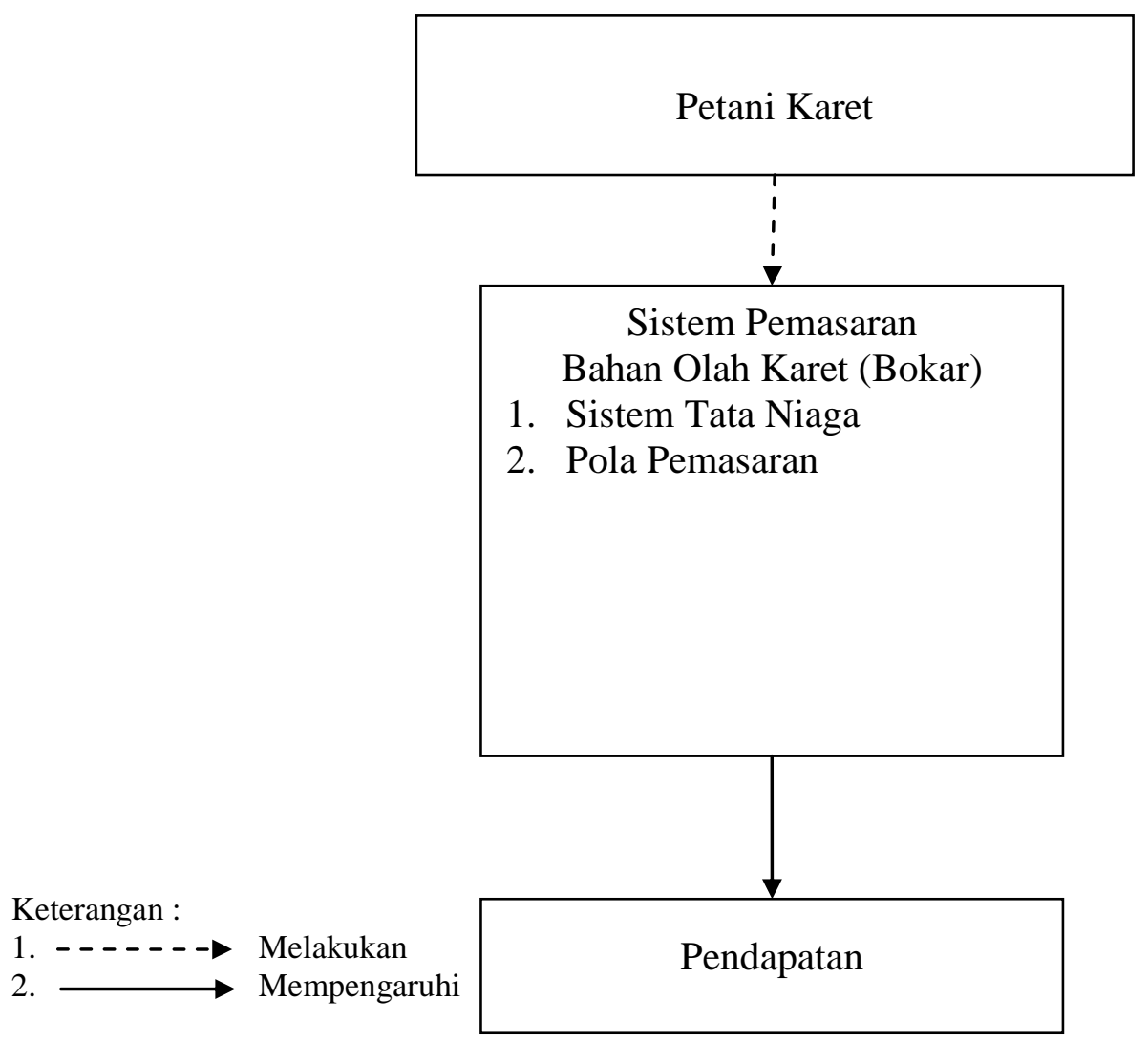

Gambar 1. Model Pendekatan Penelitian Secara Diagramatik 


\section{HASIL DAN PEMBAHASAN}

\section{Sistem Pemasaran Bahan Olah Karet (Bokar) di Desa Surya Adi Kecamatan Mesuji Kabupaten Ogan Komering Ilir.}

Pemasaran bokar di Desa Surya Adi Kecamatan Mesuji Kabupaten Ogan Komering Ilir belum terorganisir dengan baik hal ini sebabkan oleh rantai pemasaran yang panjang dan mutu bokar yang rendah. Penyebab lainnya adalah sistem penjualan bokar yang masih didasarkan atas berat basah sehingga bokar yang diperdagangkan hanya berkadar 45-55 persen selebihnya adalah air dan kotoran, karena kondisi ini menyebabkan biaya angkut yang tinggi dan ada resiko susut yang harus ditanggung oleh pedagang pengepul dan akhirnya berpengaruh terhadap harga, belum lagi harga jual tergantung pada tengkulak (pedagang pengepul) karena berdasarkan rantai pemasaran bokar di Desa Surya Adi Kecamatan Mesuji Kabupaten Ogan Komering Ilir petani rata-rata menjual bokar kepada tengkulak. Sistem pembelian yang dilakukan tengkulak dalam membeli bokar menetapkan potongan berat sebesar $10 \%$ dengan kesepakatan yang telah disetujui oleh petani. Berikut ini rantai pemasaran bokar di Desa Surya Adi Kecamatan Mesuji Kabupaten Ogan Komering Ilir :

1. Petani $\rightarrow$ Pengepul Kecil $\rightarrow$ Pengepul Besar $\rightarrow$ Pabrik

Rantai pemasaran bokar yang pertama, proses penjualan bokar tidak terorginisir dengan baik karena tidak adanya penyortiran dan rata-rata bahan pembeku yang digunakan adalah Pupuk SP 36 dan pembayaran bokar lebih cepat.

2. Petani $\rightarrow$ Pengepul Besar $\rightarrow$ Supplier Pabrik

Rantai pemasaran bokar yang kedua, proses penjualan bokar melalui proses sortir, bahan pembeku yang digunakan ratarata menggunakan tawas.

3. Petani $\rightarrow$ Kelompok Tani $\rightarrow$ Pabrik

Rantai pemasaran bokar ketiga, proses pembayaran bokar lama, bahan pembeku yang digunakan yaitu asam semut, bokar harus berkualitas baik (sesuai persyaratan mutu teknis bokar) dan penjualan bokar terorganisir dengan baik.

Dari ketiga rantai pemasaran bokar yang ada di Desa Surya Adi Kecamatan Mesuji Kabupaten Ogan Komering Ilir persentase petani yang memilih rantai pemasaran pertama sebesar $60 \%$, kedua sebesar $25 \%$ dan ketiga sebesar $15 \%$. Petani di Desa Surya Adi Kecamatan Mesuji Kabupaten Ogan Komering Ilir ratarata memilih rantai pemasaran yang pertama karena proses penjualan lebih cepat (proses sortir tidak ada) dan sebagian petani terikat utang dengan tengkulak (pedagang pengepul) serta penjualan bokar tidak terorganisir dengan baik. Sesuai dengan rantai pemasaran bokar yang ada di Desa Surya Adi Kecamatan Mesuji Kabupaten Ogan Komering Ilir sebaiknya petani lebih memilih rantai pemasaran yang ketiga karena bokar berkualitas baik (sesuai persyaratan mutu teknis bokar), proses penjualan teroginisir dengan baik serta harga bokar menjadi lebih tinggi. 


\section{Pendapatan petani karet di Desa Surya Adi Kecamatan Mesuji Kabupaten Ogan Komering Ilir} Biaya produksi dalam usahatani ini mencakupi biaya pupuk, biaya pestisida, biaya tenaga kerja dan biaya penyusutan alat serta biaya lain-lain. Adapun rincian Biaya Produksi Petani karet di Desa Surya Adi sebagai berikut :

Tabel 1. Rata-Rata Biaya Produksi Petani Karet di Desa Surya Adi Kecamatan Mesuji Kabupaten Ogan Komering Ilir.

\begin{tabular}{|c|c|c|}
\hline No & Jenis Alat & $\begin{array}{c}\text { Jumlah } \\
\text { (Rp/Ha/Bln) }\end{array}$ \\
\hline 1 & Biaya pupuk & 396.237 \\
\hline 2 & Biaya herbisida & 75.291 \\
\hline 3 & Biaya penyusutan alat & 101.900 \\
\hline 3 & Biaya bahan pembeku & 184.123 \\
\hline \multirow[t]{2}{*}{4} & Biaya tenaga kerja & 302.167 \\
\hline & Total & 1.059 .717 \\
\hline
\end{tabular}

Produksi usahatani karet ini berjumlah $58.856 \mathrm{~kg} / \mathrm{bln}$ dengan rata-rata produksi $1.509 \mathrm{~kg} / \mathrm{bln}$. Dalam mengusahakan usahataninya setiap petani memiliki lahan 2,00 ha sampai 15,00 ha, jenis karet yang sama (PB 260), serta waktu penanaman yang sama (Tahun 1986). Hal ini karena kebun tersebut merupakan jatah transmigrasi. Akan tetapi hasil produksi yang diterima petani sekarang sangat bervariasi antara petani karet yang satu dengan yang lainnya (ada yang mendapatkan hasil produksi yang tinggi dan adapula yang rendah). Adanya perbedaan hasil produksi yang jauh bagi petani karet di Desa Surya Adi disebabkan oleh adanya kebakaran hutan yang besar di sekitar desa tersebut pada tahun 1998, sehingga sebagian dari kebun karet petani ikut mengalami kebakaran.

Dari peristiwa tersebut sebagian petani mengadakan peremajaan tanaman dan ada pula yang hanya menyadap sisa hasil tanaman karet yang tidak ikut terbakar.

Berikut ini rata-rata jumlah luas tanam, produksi, penerimaan dan pendapatan usaha tani karet di Desa Surya Adi Kecamatan Mesuji Kabupaten Ogan Komering Ilir pada tabel di bawah ini :

Tabel 2. Rata-Rata Jumlah Luas Tanam, Produksi, Penerimaan dan Pendapatan Usaha Tani Karet di Desa Surya Adi Kecamatan Mesuji Kabupaten Ogan Komering Ilir.

\begin{tabular}{llr}
\hline No & \multicolumn{1}{c}{ Uraian } & Jumlah \\
\hline 1. & Luas Tanam (Ha) & 5 \\
2. & Produksi (Kg/Bln) & 1.509 \\
3. & Penerimaan (Rp/Bln) & 9.809 .333 \\
4. & Biaya Produksi (Rp/Bln) & 1.059 .717 \\
5. & Pendapatan (Rp/Bln/Ha) & 1.578 .679 \\
\hline & Sumber : Data Primer (diolah), 2015
\end{tabular}


Pada saat penelitian hasil produksi yang dijual petani yaitu karet berupa lump (latek yang telah dibekukan dengan menggunakan bahan pembeku seperti asam cuka, SP 36 dan tawas). Adapun rata-rata luas tanam sebesar 5 , Ha dan jumlah produksi sebesar $58.856 \mathrm{~kg} / \mathrm{bln}$. Harga jual satuan produksi karet adalah Rp 6.500 per kg maka jumlah penerimaan dalam satu bulan adalah $\mathrm{Rp} 382.564 .000$ per bulan dengan rata-rata penerimaan $\mathrm{Rp}$ 9.809.333.

Pendapatan Usaha Tani Karet di Desa Surya Adi Kecamatan Mesuji Kabupaten Ogan Komering Ilir dengan jumlah pendapatan sebesar Rp.61.930.729 per bulan/hektar dan ratarata pendapatan sebesar Rp.1.587.967 per bulan/hektar.

\section{KESIMPULAN DAN SARAN}

Pemasaran bokar di Desa Surya Adi Kecamatan Mesuji Kabupaten Ogan Komering Ilir belum terorganisir dengan baik hal ini disebabkan oleh rantai pemasaran yang panjang dan mutu bokar yang rendah. Sistem penjualan yang ada di Desa Surya Adi Kecamatan Mesuji Kabupaten Ogan Komering Ilir bokar mingguan, petani menjual bokar dengan tengkulak (pedagang sementara) sebesar Rp.6.500. Pendapatan yang diperoleh petani dalam 1 bulan adalah dengan ratarata Rp.1.587.967 per bulan/ha.

\section{DAFTAR PUSTAKA}

Badan Standarisasi Nasional, 2002. Standar Nasional Indonesia Bahan Olah Karet (SNI 06-20472002). BSN

Budiono, 2011. Sejarah dan Prospek Pengembangan Karet Balai Penelitian Getas Salatiga (http://www.wordpress.com, diakses tanggal 16 Januari 2015).
Setiawan, P. 2005. Teknik Penyadapan Karet, Kanisus. Yogyakarta.

Permendag, 2014. Materi Sosialisasi UPPb2.1. (http://www.gapkindo.org/index.p $\underline{\mathrm{hp}}$, diakses tanggal 26 Januari 2015)

Winardi, K.A 2007. Seuntai Pengetahuan Dunia Ketiga. Erlangga, Jakarta. 